\section{Response to: 'Drugs and cardiovascular risk in inflammatory arthritis: another case of glucocorticoid-bashing?' by Dr Boers}

We thank Dr Boers for the interesting comments ${ }^{1}$ on our paper $^{2}$. First, the decision to exclude studies reporting less than 400 patients was made after noticing that most of these studies had less than 1 year of follow-up or had large drop-outs with few remaining patients at or beyond 1 year. We also reviewed the abstract by Tarp et al. ${ }^{3}$ Among a total of 4831 subjects, 1944 were specifically analysed for cardiovascular purpose; no statistically significant increase in cardiovascular diseases was found in subjects treated with glucocorticoids. Of note, given that this is an abstract, we had no precise data regarding inclusion and exclusion criteria, as well as references of the included randomised controlled trials. Some lack of statistical power may be hypothesised because of low sample size. Our meta-analysis exploring the association between the use of glucocorticoids and cardiovascular events, analysed a total of 83205 subjects included in 11 observational studies. Importantly, the median study duration of 24 weeks, may not be sufficient to report cardiovascular events, and to ensure that the impact of glucocorticoids was a true effect and not due to chance in a short duration of observation. Second, we agree with Dr Boers that observational studies may suffer from some channelling biases, but specifically regarding glucocorticoids the evidence is so overwhelming for all the outcomes studied pointing in the same direction, that it would be difficult to speculate that unaccounted confounding factors could have altered the data in a significant manner. Finally, the purpose of this review was not to balance cardiovascular effects of the studied drugs against their potential benefits, and definitely not to specifically bash glucocorticoids since we did not address other potential side effects. In one of our meta-analyses on the effects of bone density in RA and seronegative arthritis, we found that in rheumatoid arthritis (RA), glucocorticoids improved bone mass in the wrist (likely due to decreasing inflammation) but worsened bone mass elsewhere. ${ }^{4}$ However, we should be reminded that it is now part of all recommendations including the European League Against Rheumatism, to limit the use of glucocorticoids to the lowest dose and for the shortest duration possible.

Camille Roubille, ${ }^{1}$ Vincent Richer, ${ }^{2}$ Tara Starnino, ${ }^{3}$ Collette McCourt, ${ }^{4}$ Alexandra McFarlane, ${ }^{5}$ Patrick Fleming ${ }^{6}$ Stephanie Siu, $^{7}$ John Kraft, ${ }^{8}$ Charles Lynde, ${ }^{8}$ Janet Pope, ${ }^{7}$ Wayne Gulliver, ${ }^{9}$ Stephanie Keeling, ${ }^{5}$ Jan Dutz, ${ }^{4}$ Louis Bessette, ${ }^{10}$ Robert Bissonnette, ${ }^{11}$ Boulos Haraoui ${ }^{12}$

${ }^{1}$ University of Montreal Hospital Research Center (CRCHUM), Montreal, Quebec, Canada
${ }^{2}$ Department of Medicine, Dermatology Service, St-Luc Hospital, Montreal, Quebec, Canada

${ }^{3}$ Sacré-Coeur Hospital of Montreal, University of Montreal, Montreal, Quebec, Canada

${ }^{4}$ Department of Dermatology and Skin Science, University of British Columbia, Vancouver, British Columbia, Canada

${ }^{5}$ Division of Rheumatology, University of Alberta, Edmonton, Alberta, Canada

${ }^{6}$ Division of Dermatology, University of Toronto, Toronto, Ontario, Canada

${ }^{7}$ Division of Rheumatology, Department of Medicine, Western University of Canada,

St. Joseph's Health Care, London, Ontario, Canada

${ }^{8}$ Lynde Dermatology, Markham, Ontario, Canada

${ }^{9}$ Faculty of Medicine, Memorial University of Newfoundland, St. John's,

Newfoundland, Canada

${ }^{10}$ Department of Medicine, Centre de Recherche du CHU de Québec, Laval University, Quebec City, Quebec, Canada

${ }^{11}$ Innovaderm Research, Montreal, Quebec, Canada

${ }^{12}$ Department of Medicine, Rheumatic Disease Unit, Centre Hospitalier de I'Université de Montréal (CHUM) and Institut de Rhumatologie de Montréal, Montreal, Quebec, Canada

Correspondence to Dr Boulos Haraoui, Institut de Rhumatologie de Montreal, 1551 Ontario Street East, Montreal, Quebec, Canada H2L 1S6; boulos.haraoui@ ssss.gouv.qc.ca

\section{Competing interests None.}

Provenance and peer review Commissioned; internally peer reviewed.

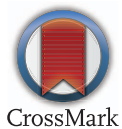

To cite Roubille C, Richer V, Starnino T, et al. Ann Rheum Dis 2015;74:e34.

Received 14 February 2015

Accepted 15 February 2015

Published Online First 9 March 2015

\section{(5) Linked}

http://dx.doi.org/10.1136/annrheumdis-2015-207412

Ann Rheum Dis 2015;74:e34. doi:10.1136/annrheumdis-2015-207419

\section{REFERENCES}

1 Boers M. Drugs and cardiovascular risk in inflammatory arthritis: another case of glucocorticoid-bashing?. Ann Rheum Dis 2015;74:e33.

2 Roubille C, Richer V, Stamino T, et al. The effects of tumour necrosis factor inhibitors, methotrexate, non-steroidal anti-inflammatory drugs and corticosteroids on cardiovascular events in rheumatoid arthritis, psoriasis and psoriatic arthritis: a systematic review and meta-analysis. Ann Rheum Dis 2015;74:480-9.

3 Tarp S, Bartels EM, Kirwan JR, et al. Adverse effects of glucocorticoid therapy in rheumatoid arthritis: a systematic review and meta-analysis of randomized controlled trials. Ann Rheum Dis 2012;71(Suppl 3):207.

4 Siu S, Haraoui B, Bissonnette R, A meta-analysis of tumor necrosis factor inhibitors and glucocorticoids on bone density in rheumatoid arthritis and ankylosing spondylitis trials. Arthritis Care Res (Hoboken). Published Online First: 21 Nov 2014. doi:10.1002/acr.22519 